\title{
Factors associated with 30-day and 1-year readmission among psychiatric inpatients in Beijing China: a retrospective, medical record-based analysis
}

Xueyan Han ${ }^{1}$, Feng Jiang ${ }^{1}$, Yilang Tang ${ }^{2,3}$, Jack Needleman ${ }^{4}$, Moning Guo ${ }^{5}$, Yin Chen ${ }^{6}$, Huixuan Zhou ${ }^{1,7}$ and Yuanli Liu ${ }^{1 *}$

\begin{abstract}
Background: Psychiatric readmissions negatively impact patients and their families while increasing healthcare costs. This study aimed at investigating factors associated with psychiatric readmissions within 30 days and 1 year of the index admissions and exploring the possibilities of monitoring and improving psychiatric care quality in China.

Methods: Data on index admission, subsequent admission(s), clinical and hospital-related factors were extracted in the inpatient medical record database covering 10 secondary and tertiary psychiatric hospitals in Beijing, China. Logistic regressions were used to examine the associations between 30-day and 1-year readmissions plus frequent readmissions ( $\geq 3$ times/year), and clinical variables as well as hospital characteristics.

Results: The 30-day and 1-year psychiatric readmission rates were 16.69\% (1289/7724) and 33.79\% (2492/7374) respectively. 746/2492 patients (29.34\%) were readmitted 3 times or more within a year (frequent readmissions). Factors significantly associated with the risk of both 30-day and 1-year readmission were residing in an urban area, having medical comorbidities, previous psychiatric admission(s), length of stay $>60$ days in the index admission and being treated in tertiary hospitals $(p<0.001)$. Male patients were more likely to have frequent readmissions (OR 1.30, 95\%Cl 1.04-1.64). Receiving electroconvulsive therapy (ECT) was significantly associated with a lower risk of 30-day readmission (OR $0.72,95 \% \mathrm{Cl} 0.56-0.91$ ) and frequent readmissions (OR $0.60,95 \% \mathrm{Cl} 0.40-0.91)$.

Conclusion: More than $30 \%$ of the psychiatric inpatients were readmitted within 1 year. Urban residents, those with medical comorbidities and previous psychiatric admission(s) or a longer length of stay were more likely to be readmitted, and men are more likely to be frequently readmitted. ECT treatment may reduce the likelihood of 30day readmission and frequent admissions. Targeted interventions should be designed and piloted to effectively monitor and reduce psychiatric readmissions.
\end{abstract}

Keywords: Psychiatric readmission, Psychiatric hospitals, China, Frequent readmissions, Comorbidities, Electroconvulsive therapy

\footnotetext{
* Correspondence: liuyl_fpo@126.com

'School of public health, Chinese Academy of Medical Sciences and Peking

Union Medical College, No.3 Dong Dan San Tiao, Dongcheng District, Beijing, China

Full list of author information is available at the end of the article
}

(c) The Author(s). 2020 Open Access This article is licensed under a Creative Commons Attribution 4.0 International License, which permits use, sharing, adaptation, distribution and reproduction in any medium or format, as long as you give appropriate credit to the original author(s) and the source, provide a link to the Creative Commons licence, and indicate if changes were made. The images or other third party material in this article are included in the article's Creative Commons licence, unless indicated otherwise in a credit line to the material. If material is not included in the article's Creative Commons licence and your intended use is not permitted by statutory regulation or exceeds the permitted use, you will need to obtain permission directly from the copyright holder. To view a copy of this licence, visit http://creativecommons.org/licenses/by/4.0/ The Creative Commons Public Domain Dedication waiver (http://creativecommons.org/publicdomain/zero/1.0/) applies to the data made available in this article, unless otherwise stated in a credit line to the data. 


\section{Background}

According to the China Mental Health Survey, the lifetime prevalence of mental disorders was estimated to be $16.6 \%$ in China [1], indicating a significant disease burden. Psychiatric patients are prone to readmissions [2]: almost 1 in 7 psychiatric patients needed to be rehospitalized within 30 days of discharge [3], and around $40 \%$ of the patients were readmitted 1 year after the index admissions [4]. Understanding the factors associated with readmission may provide important references to predict or prevent readmissions and/or frequent hospitalizations [5].

Although repeated hospitalizations for patients with psychiatric disorders may reflect the nature and course of the illnesses, socio-demographic or environmental factors, underlying inefficiencies during the hospitalization and in the pre- and post-discharge settings may also play a role [6]. Readmissions may be disruptive to patients and their families and place a strain on already limited healthcare resources. Moreover, repeated admissions could encourage dependency on inpatient services [7] and increase healthcare costs [5]. Therefore, readmission has long been recognized as a validated outcome measure for healthcare quality [8]. The commonly used timeframes to assess readmission were readmission within 30 days $[3,5,7,9]$ and 1 year $[2,7,10]$. As for the frequency of readmissions, Langdon et al. considered the patients that experienced three or more admissions a year to be "the revolving door" patients [11].

Previous studies have identified several factors associated with psychiatric readmissions, although some of these factors were found to be specific to settings and timeframes and the findings were somewhat mixed [5, 7]. Literature review showed that the following factors have been examined: 1) Socio-demographic factors: patients' sex [4], age [11], marital status, insurance type, employment status, income level, care-giver information, living condition [12], education level and location of residency [5]; 2) Clinical factors: the previous service use [3], whether a patient was detained by law enforcement or was admitted involuntary [7], primary discharge diagnosis [13], illness severity (determined by various scales), various medical comorbidities [14], use of electroconvulsive therapy (ECT) [15], inpatient length of stay [16]; 3) Post-discharge factors: medication adherence [17], suicide attempts, family and social support, use of primary/ community healthcare services; 4) Hospital characteristics: the hospital type, size [15] and location [9].

Most of the existing studies were conducted in developed countries, where the psychiatric care had been drastically reshaped after the de-institutionalization movement [4] and the expansion of community-based services. Few studies have been done in developing countries [10], where mental health services are vastly different in resource allocation and structure. For example, mental health services in China are mostly organized around psychiatric hospitals, which provide nearly $80 \%$ of mental health services $(78.8 \%$ of all beds, and $78.4 \%$ of mental health workers) in the country $[18,19]$. Therefore, it is of importance to study the pattern of psychiatric readmission and the associated factors in China.

China is currently facing a shortage in psychiatric beds and mental health professionals. For example, a recent study pointed out that there were 3.15 psychiatric beds per 10,000 population in China, nearly half of the rate in high-income countries (7.13 beds per 10,000 population) [20]. At the same time, the distribution of the already insufficient mental care resources is highly uneven. The community mental health services and mental health services in general hospitals are scarce [21]. Patients often tended to bypass the primary and secondary care and seek treatment directly in tertiary psychiatric hospitals [22], which are mainly located in urban areas of the more developed regions [23]. The lack of care coordination and psychiatric rehabilitation facilities also led to prolonged hospital stays (average psychiatric inpatient length of stay in China was 50-60 days in 2017 [24]).

Furthermore, China is a geographically vast country, and regional differences in service volume and clinical practice may exist. Take ECT treatment as an example, a survey of 45 psychiatric hospitals from 10 provinces in China, showed that the rates of ECT utilization among schizophrenia patients varied from $0.5 \%$ in Jiangsu province (eastern China) to $12.2 \%$ in Jilin province (northeast China) [25].

A few previous studies have focused on psychiatric readmission in patients in China. Zhou et al. (2014) identified previous hospitalizations to be significantly associated with 1-year readmission [2]. Zhang and Dai identified that being married, living with family members, low disease severity and good medication adherence were associated with a lower risk of readmission among 963 patients [26]. However, most of these studies were based on small sample sizes [27, 28] or based on patient records of a single hospital $[29,30]$.

To address this research gap, we designed this study, which aimed to investigate factors associated with 30day and 1-year psychiatric readmissions as well as frequent readmissions ( $\geq 3$ times/year). We utilized a regional, multi-center database to ensure a larger sample size and examine hospital-level variables. This study also utilized an all-payer database that included inpatient records regardless of their insurance types or payment methods, thus allowing us to include uninsured patients or patients covered by insurances other than the 3 main social health insurance schemes in China (namely the Urban employee basic medical insurance, Urban resident 
basic medical insurance and New cooperative medical scheme) [31].

\section{Methods}

\section{Data source}

The initial dataset was obtained from the Beijing Municipal Health Commission Information Centre (referred as the Information Centre). It contained data extracted from the face sheets of inpatient medical records [32] uploaded from 186 secondary and tertiary hospitals in Beijing city, China. The data used in this study was from the year 2015 to 2017. The databases covered 84.93\% $(186 / 219)$ of all the secondary and tertiary, public and private hospitals in Beijing [33], and included 10
(71.42\%) out of 14 secondary and tertiary specialty psychiatric hospitals in the city [24].

The eligibility criteria of the index admissions and the data cleaning process were illustrated in Fig. 1. Each unique patient was identified using a patient identifier, which was generated and provided by the Information Centre. The patient identifier was a series of numbers unique to each patient and was used to recognize patients across time and different hospitals. This identifier contained no traceable personally identifiable information of the patients. Other variables used to filter eligible records were: hospital category code (to differentiate psychiatric hospitals from general hospitals), discharge destination code (to identify and exclude in-hospital deaths), primary diagnosis, date of admission and

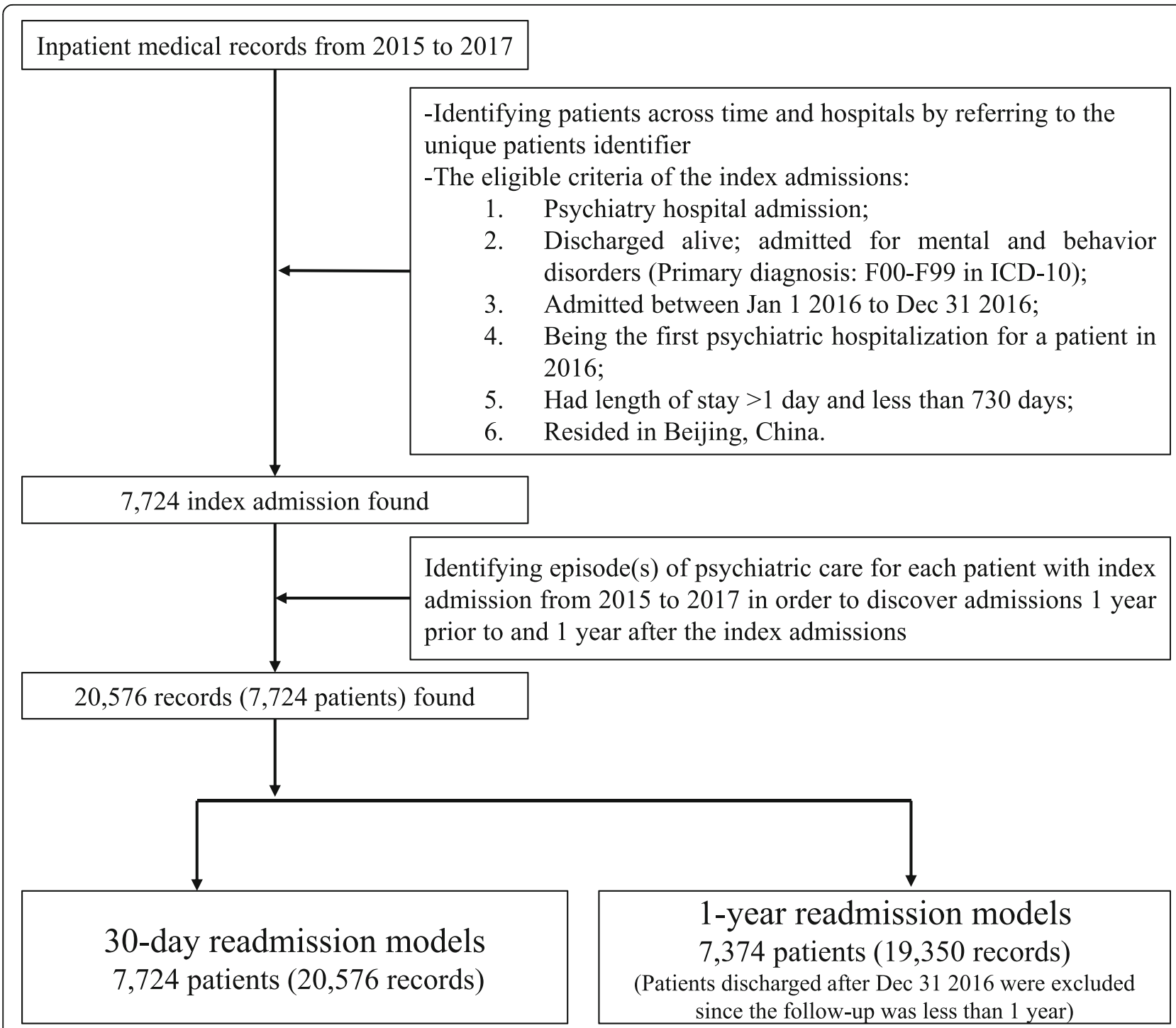

Fig. 1 Flow chart for data cleansing and the identification of index admissions. Figure 1 illustrated the data cleansing and sample identification process of the study. It specified the eligibility criteria of the index admissions and the records included for both the 31-day and the 1-year psychiatric readmission models 
discharge, inpatient length of stay (LOS) and postal code of patients' present address (to identify if the patients were residing in Beijing). Readmissions within $24 \mathrm{~h}$ of the last discharge were excluded as they were considered as planned admission or planned patient transfer [2]. Psychiatric inpatient stays for $24 \mathrm{~h}$ or less were not considered an index or readmissions since the patients were likely to be hospitalized for scheduled rehabilitation.

This project was approved by the Ethics Committee of Chinese Clinical Trial Registry (ChiECRCT-20,180,166). The informed consent of patients was waived.

\section{Study design Model design}

We constructed 3 multi-variate logistic models primarily: 1 ) the 30-day readmission model. The dependent variable was a binary variable indicating 30-day readmissions status (yes or no). All the eligible index admissions were included in this model; 2) the 365-day (1-year) readmission model. The dependent variable of this model was a binary variable indicating 365-day readmissions status (yes or no). The eligible index admissions with a discharge date after Dec 31, 2016 were excluded in this model. We applied this exclusion because we only had inpatient records up to Dec 31, 2017; 3) the frequent readmissions model. The dependent variable of this model was a binary variable with patients who had three or more psychiatric readmissions within 365 days of the index admissions versus patients with at least one and less than 3 readmissions within 365 days. The eligible index admissions with a discharge date after Dec 31, 2016 as well as eligible index admissions that were not followed by any readmission within 365 days after the index admissions were excluded. This model was designed to explore factors associated with repeated readmissions.

We used the same set of independent variables for these three models. We only included admissions with primary diagnoses of mental and behavioral disorders (ICD-10 code: F00-F99). We did not include admissions for non-psychiatric conditions within the timeframe.

\section{Independent variables}

We included a set of variables based on literature review and availability in our database. The variables included in this study were socio-demographic factors (sex [4], age, marital status, insurance type [2], patients' residency (urban/rural) (based on their postal codes and the city planning of Beijing)); primary diagnostic categories (ICD 10 codes: depressive disorder (F32-F33), bipolar disorder (F31), schizophrenia and related disorder (F20-F29), substance use disorder (F10-F19), and other psychiatric disorders); number of medical comorbidities [14] (31 comorbidities defined in the AHRQ Elixhauser comorbidity index [14, 34, 35] were identified using the Stata module "ELIXHAUSER" and counted); treatment-related factors (use of electroconvulsive therapy (ECT) [15] (identified by the ICD-9-CM-3 code for ECT, 94.27)); previous admission(s) 1 year prior to the index admissions [5] (none, 1 times, 2 times, 3 times or more) (matched using patient identifier across hospitals and years); length of stay (days); as well as institutional factors [5, 15], including hospital level (tertiary or secondary) and hospital location (urban or rural). The comorbidities listed in the Elixhauser comorbidity index included cardiovascular conditions liver and renal diseases [36] (See Supplementary Table 1 in Additional File 1 for details). The Elixhauser comorbidity index has been used previously in riskadjustment methodologies and predictive models [34].

\section{Statistical analyses}

Descriptive analyses were conducted to show distributions of the independent variables in the entire sample and in the readmitted patients. Chi square analyses were applied to categorical variables and the Wilcoxon ranksum test was applied to continuous variables to determine whether there were significant differences in groups with different readmission status.

Statistical inference was conducted using logistic regression. We used univariate logistic regressions first to examine the unadjusted effect between the different factors and the risk of readmission. We then used multivariable logistic regressions on each dependent variable and generated estimates for all the independent variables. Unadjusted and adjusted odds ratios and 95\% confidence intervals were reported. The pseudo R-square were reported for each model to show the general model performance. The variance inflation factors (VIF) for the models were also calculated to flag multi-collinearity. For model discrimination and calibration, the C-statistic was calculated from the receiver-operator characteristic curve to assess model discrimination, where a C-statistic of 0.50 or more indicates acceptable predictive power [37]. Hosmer-Lemeshow goodness-of-fit tests were applied and the calibration plots were generated for each model to assess model calibration [38].

To check the robustness of the results, we conducted sensitivity analyses to examine the same set of factors for index admissions for patients with schizophrenia and related disorders (F20-F29 as their primary diagnosis) and affective disorders (with F30-F39 as their primary diagnosis) respectively. All analyses were conducted using the Stata, version 15 (StataCorpLP, College Station, TX, USA). All $P$-values were two-sided and were considered significant at $p<0.05$.

\section{Results}

Patient characteristics

Among the 7724 patients (index admissions) included in the analyses, 1289 patients $(1289 / 7724,16.69 \%)$ were 
readmitted within 30 days, and 2492/7374 (33.79\%) were readmitted within 1 year after the index admissions in which $746 / 2492$ patients (29.94\%) were readmitted 3 or more times (Table 1). Among the 10 hospitals, 3 were tertiary hospitals and 5 were located in an urban area.

Regarding the sociodemographic factors, $51.99 \%$ of the included patients were female, the mean age was 46.71 years old (standard deviation: 17.02 years), nearly half of the patients were married (48.90\%), and $87.52 \%$ had health insurance coverage. Clinically, more than one fourth $(26.39 \%)$ had previous admission(s) within a year prior to the index admissions. The largest diagnosis group was schizophrenia and related disorders (44.64\%), followed by bipolar disorders (31.17\%). More than half of the sample (57.69\%) had at least 1 medical comorbidity listed in the Elixhauser comorbidity index. The mean inpatient length of stay (LOS) was 66.90 days, with a great range of variation (median: 36 days; interquartile range: 60 days; standard deviation: 78.70 days). Details about the basic features of the sample can be found in the Additional File 1 (Supplementary Table 2-4).

\section{Thirty-day readmissions and associated factors}

For unadjusted analyses, sex, age, marital status and primary diagnosis group were all significantly associated with readmission risk but none of them were statistically significant in the multi-variable regression model. The variables that were significantly associated with the risk of 30day readmission including an urban residency, medical comorbidities, prior psychiatry hospitalizations in the previous year, longer inpatient length of stay ( $>60$ days), as well as being treated in tertiary hospitals $(p<0.001)$ (Table 2$)$. The use of ECT was significantly associated with a low risk of 30-day readmission. The Pseudo- $\mathrm{R}^{2}$ of this model was 0.35 and $\mathrm{C}$-statistics was 0.87 , indicating acceptable predicting power. Detailed test results of model discrimination and calibration can be found in the Additional File 1 (Supplementary Table 8).

\section{One-year readmission and associated factors}

We found being married was significantly associated with a low risk of 1 -year readmission risk $(p<0.05)$. Compared to patients with depressive disorders, patients with bipolar disorders and schizophrenia and related disorders were significantly associated with risk of 1 -year readmission $(p<0.001)$. Full results are displayed in Table 2. ECT was significantly associated with a low risk of readmission in the univariate model, but the significance disappeared in the multi-variable analysis. The Pseudo- $R^{2}$ of this model was 0.23 and C-statistics was 0.78 .

\section{Factors associated with 1-year frequent readmissions}

Among 2492 patients who were readmitted at least once within a year after the index admissions, nearly one third
(29.94\%) were readmitted for 3 or more times (frequent readmission). Compared with those with 1 or 2 readmissions, being male, residing in an urban area, having medical comorbidities, previous hospitalizations and being treated in a tertiary hospital were significantly associated with risk of frequent readmissions (Table 3). The use of ECT was associated with a lower risk of frequent readmission (OR: 0.60, 95\%CI: 0.40-0.91). The Pseudo- $\mathrm{R}^{2}$ was 0.31 and $\mathrm{C}$-statistics was 0.86 for this model.

\section{Sensitivity analyses}

The results for models in the sensitivity analyses as well as the post-regression diagnostics tests were presented in the Additional File 1 (Supplementary Table 5-9). The models including patients with schizophrenia and related disorders basically showed consistent results with the full models that included all the patients. The association between the use of ECT and low readmission risk was found in the schizophrenia models, but the association was not significant in the affective disorder models, regardless of readmission interval or frequency.

\section{Discussion}

\section{Main findings}

This study investigated the factors associated with risk of psychiatric readmission within 30 days and 1 year after the index admissions in the regional all-payer database of Beijing, China. The 30-day and 1-year psychiatric readmission rates were 16.69 and $33.79 \%$ respectively and 746 patients out of 7374 patients $(10.12 \%)$ were re-admitted three times or more within a year. Several factors were significantly associated with a high risk of 30-day and 1-year readmission, including an urban residency, having more medical comorbidities and previous psychiatric admission(s), a length of stay of $>60$ days in the index admission as well as being treated in tertiary hospitals. The use of ECT was significantly associated with a lower risk of 30day readmissions and frequent readmissions in the whole sample and the schizophrenia subgroup.

\section{Psychiatric readmission rates}

The 30 -day readmission rate $(16.69 \%)$ in this study was consistent with some studies conducted in other countries and settings [7, 9]; nevertheless, the 30-day readmission rate had large variations from previous reports. A report published by the Organization for Economic Cooperation and Development suggested that the 30-day readmission rate for schizophrenia varied from 5 to $20 \%$ among 20 countries [39] and the 30-day readmission rate was $4.5 \%$ $(1598 / 37,796)$ in a Korean sample [8]. The 1-year readmission rate $(33.79 \%)$ in our study is similar to that reported in other studies $[10,40]$ except the one reported by Zhou el al. (2014) which reported the 1-year readmission rate as $13.8 \%$ (476/3455) in one hospital in Guangzhou city [2]. 
Table 1 Social-demographic and clinical characteristics of included patients

\begin{tabular}{|c|c|c|c|c|c|}
\hline \multirow[b]{2}{*}{ Characteristics (n (\%)) } & \multicolumn{2}{|c|}{ 30-day readmission $(N=7724)$} & \multicolumn{3}{|c|}{ 1-year readmission $(N=7374)$} \\
\hline & All & $\begin{array}{l}\text { Readmitted } \\
(n=1289 / 7724)\end{array}$ & All & $\begin{array}{l}\text { Readmitted } \\
(n=2492 / 7374)\end{array}$ & $\begin{array}{l}\text { Readmitted } \geq 3 \\
\text { times }(n=746 / 2492)\end{array}$ \\
\hline Gender: male & $3708(48.01)$ & $713(55.31)$ & $3525(47.8)$ & $1318(52.89)$ & $465(62.33)$ \\
\hline Age (mean, SD) & $46.71(17.02)$ & $54.71(16.10)$ & $46.27(17.06)$ & $50.50(17.07)$ & $58.05(15.24)$ \\
\hline \multicolumn{6}{|l|}{ Insurance* } \\
\hline Urban employee & $4350(56.32)$ & $979(75.95)$ & $4138(56.12)$ & $1707(68.5)$ & $629(84.32)$ \\
\hline Urban resident & 859 (11.12) & $82(6.36)$ & 795 (10.78) & $242(9.71)$ & $42(5.63)$ \\
\hline New rural cooperative & $633(8.20)$ & $49(3.80)$ & $600(8.14)$ & $116(4.65)$ & $10(1.34)$ \\
\hline Other insurances & $918(11.89)$ & $110(8.53)$ & $946(12.83)$ & $189(7.58)$ & $19(2.55)$ \\
\hline Non-insured & $964(12.48)$ & $69(5.35)$ & $895(12.14)$ & $238(9.55)$ & $46(6.17)$ \\
\hline Married & $3777(48.90)$ & $416(32.27)$ & $3668(49.74)$ & $1020(40.93)$ & $228(30.56)$ \\
\hline Urban residents & $5118(66.26)$ & $1023(79.36)$ & 4918 (66.69) & $1883(75.56)$ & $646(86.60)$ \\
\hline \multicolumn{6}{|l|}{ Diagnoses } \\
\hline Depressive disorders & $1195(15.47)$ & $71(5.51)$ & $1192(16.16)$ & $234(9.39)$ & $35(4.69)$ \\
\hline Bipolar disorders & $1635(21.17)$ & $123(9.54)$ & $1615(21.9)$ & $420(16.85)$ & $43(5.76)$ \\
\hline Schizophrenia and related disorders & $3448(44.64)$ & $893(69.28)$ & $3169(42.98)$ & $1375(55.18)$ & $517(69.30)$ \\
\hline Substance use disorders & $407(5.27)$ & $35(2.72)$ & $403(5.47)$ & $132(5.30)$ & $30(4.02)$ \\
\hline Other mental disorders & $1039(13.45)$ & $167(12.96)$ & 995 (13.49) & $331(13.28)$ & $121(16.22)$ \\
\hline \multicolumn{6}{|l|}{ Count of comorbidities ${ }^{\#}$} \\
\hline None & $3268(42.31)$ & $234(18.15)$ & $3125(43.60)$ & $645(25.88)$ & $82(10.99)$ \\
\hline 1 & $1759(22.77)$ & $287(22.27)$ & $1682(22.81)$ & $568(22.79)$ & $154(20.64)$ \\
\hline$>1$ & $2697(34.92)$ & $768(59.58)$ & 2477 (33.59) & $1279(51.32)$ & $510(68.36)$ \\
\hline Use of ECT & $2065(26.73)$ & $119(9.23)$ & $2053(27.84)$ & $451(18.10)$ & $41(5.50)$ \\
\hline \multicolumn{6}{|l|}{ Previous hospitalization(s) } \\
\hline None & $5686(73.61)$ & $395(30.64)$ & $5550(75.26)$ & $1233(49.48)$ & $122(16.35)$ \\
\hline 1 time & $1054(13.65)$ & $258(20.02)$ & $878(11.91)$ & $430(17.26)$ & $92(12.33)$ \\
\hline 2 times & $544(7.04)$ & $334(25.91)$ & $509(6.9)$ & $421(16.89)$ & $226(30.29)$ \\
\hline$\geq 3$ times & $440(5.70)$ & $302(23.43)$ & $437(5.93)$ & $408(16.37)$ & $306(41.02)$ \\
\hline \multicolumn{6}{|l|}{ Admission sources } \\
\hline Emergency room & $2528(32.73)$ & $172(13.34)$ & $2515(34.11)$ & $591(23.72)$ & $70(9.38)$ \\
\hline Outpatient & $4914(63.62)$ & $1093(84.79)$ & $4663(63.24)$ & $1848(74.16)$ & $670(89.81)$ \\
\hline Other & $282(3.65)$ & $24(1.86)$ & $196(2.66)$ & $53(2.13)$ & $6(0.80)$ \\
\hline Length of stay (mean, SD) & $66.90(78.70)$ & $115.61(75.21)$ & $55.76(55.93)$ & $79.83(63.43)$ & $101.33(50.48)$ \\
\hline \multicolumn{6}{|l|}{ Hospital type } \\
\hline Tertiary hospitals (vs secondary hospitals) & $6438(83.35)$ & $1119(86.81)$ & $6346(86.06)$ & $2135(85.67)$ & $684(91.69)$ \\
\hline Urban hospitals (vs rural hospitals) & $4591(59.44)$ & $298(23.12)$ & $4490(60.89)$ & $1084(43.50)$ & $146(19.57)$ \\
\hline
\end{tabular}

Notes: * The full titles of the first 3 insurance types are Urban employee basic medical insurance, Urban resident basic medical insurance and New cooperative medical insurance. The same goes for other tables

\# 31 comorbidities defined by the AHRQ Elixhauser Comorbidities Index were identified by the Stata module "ELIXHAUSER" and then counted. The same goes for other tables

There are several possible explanations for the different rates of readmission, including differences in patient populations, length of stay, discharge criteria and insurance coverage. The inclusion/exclusion criteria are also different from one study to another. Our study was able to track the patients even if the patients were admitted to a different hospital or changed payment methods between admissions. This study also adopted more strict inclusion criteria. For instance, current residency in Beijing was considered one of the eligibility criteria so that nonresidents would not inflate the denominator and cause an under-estimation of the readmission rate. 
Table 2 Logistic regression of analysis of readmissions in 30-days and 1 year

\begin{tabular}{|c|c|c|c|c|}
\hline & \multicolumn{2}{|c|}{ 30-day readmission model $(\mathrm{N}=7724)$} & \multicolumn{2}{|c|}{ 1-year readmission model $(N=7374))$} \\
\hline & Univariate models & Multivariate model & Univariate models & Multivariate model \\
\hline Male (ref. female) & $1.42(1.26,1.60)^{* *}$ & $0.95(0.81,1.11)$ & $1.36(1.24,1.5)^{* *}$ & $1(0.89,1.12)$ \\
\hline \multicolumn{5}{|l|}{ Age (ref. (0-40]) } \\
\hline$(40,65]$ & $2.63(2.25,3.06)^{* *}$ & $0.84(0.68,1.04)$ & $1.72(1.54,1.91)^{* *}$ & $0.8(0.69,0.92)^{* *}$ \\
\hline$>65$ & $4.71(3.90,5.68)^{* *}$ & $0.92(0.69,1.21)$ & $2.72(2.33,3.17)^{* *}$ & $0.69(0.55,0.87)^{* *}$ \\
\hline \multicolumn{5}{|l|}{ Insurance type (ref. no insurance) } \\
\hline Urban employee & $3.76(2.91,4.86)^{* *}$ & $1.19(0.88,1.6)$ & $2.81(2.37,3.34)^{* *}$ & $1.42(1.17,1.72)^{* *}$ \\
\hline Urban resident & $1.37(0.98,1.91)$ & $0.75(0.51,1.09)$ & $1.75(1.41,2.18)^{* *}$ & $1.22(0.96,1.56)$ \\
\hline New rural cooperative & $1.08(0.74,1.59)$ & $1.12(0.74,1.71)$ & $0.96(0.74,1.24)$ & $0.99(0.75,1.31)$ \\
\hline Other insurances & $1.77(1.29,2.42)^{* *}$ & $1.03(0.71,1.5)$ & $1.45(1.17,1.8)^{* *}$ & $0.86(0.76,0.99)^{*}$ \\
\hline Married (ref. not married) & $0.44(0.38,0.50)^{* *}$ & $0.86(0.72,1.02)$ & $0.58(0.53,0.64)^{* *}$ & $0.86(0.76,0.97)^{* *}$ \\
\hline Urban residents (ref. Suburb) & $2.19(1.90,2.54)^{* *}$ & $1.4(1.15,1.7)^{* *}$ & $1.88(1.69,2.1)^{* *}$ & $1.41(1.23,1.61)^{* *}$ \\
\hline \multicolumn{5}{|l|}{ Diagnosis (ref. depressive disorders) } \\
\hline Bipolar disorders & $1.29(0.95,1.74)$ & $1.1(0.79,1.54)$ & $1.44(1.2,1.72)^{* *}$ & $1.35(1.11,1.65)^{* *}$ \\
\hline Schizophrenia and related disorders & $5.53(4.30,7.12)^{* *}$ & $1.44(1.06,1.94)^{*}$ & $3.14(2.68,3.68)^{* *}$ & $1.35(1.12,1.63)^{* *}$ \\
\hline Substance use disorders & $1.49(0.98,2.27)$ & $0.64(0.4,1.04)$ & $1.99(1.55,2.57)^{* *}$ & $1.14(0.85,1.53)$ \\
\hline Other mental disorders & $3.03(2.27,4.06)^{* *}$ & $1.3(0.93,1.81)$ & $2.04(1.68,2.48)^{* *}$ & $1.18(0.94,1.47)$ \\
\hline \multicolumn{5}{|l|}{ Count of comorbidities (ref. none) } \\
\hline 1 & $2.53(2.10,3.04)^{* *}$ & $1.67(1.34,2.09)^{* *}$ & $2.03(1.78,2.32)^{* *}$ & $1.62(1.39,1.89)^{* *}$ \\
\hline$>1$ & $5.16(4.41,6.04)^{* *}$ & $2.17(1.75,2.7)^{* *}$ & $4.25(3.78,4.78)^{* *}$ & $2.63(2.25,3.07)^{* *}$ \\
\hline Use of ECT (ref. no ECT) & $0.23(0.19,0.29)^{* *}$ & $0.72(0.56,0.91)^{* *}$ & $0.45(0.4,0.51)^{* *}$ & $0.91(0.79,1.05)$ \\
\hline \multicolumn{5}{|c|}{ Psychiatric hospitalizations 1 year prior to index admission (ref. none) } \\
\hline 1 & $4.34(3.65,5.17)^{* *}$ & $1.91(1.55,2.36)^{* *}$ & $3.36(2.9,3.89)^{* *}$ & $1.96(1.66,2.31)^{* *}$ \\
\hline 2 & $21.30(17.43,26.04)^{* *}$ & $4.87(3.8,6.24)^{* *}$ & $16.75(13.2,21.26)^{* *}$ & $6.19(4.76,8.05)^{* *}$ \\
\hline$\geq 3$ times & $28.31(23.39,36.74)^{* *}$ & $5.12(3.87,6.78)^{* *}$ & $49.26(33.62,72.17)^{* *}$ & $15.84(10.58,23.72)^{* *}$ \\
\hline \multicolumn{5}{|l|}{ Admission sources (ref. emergency room) } \\
\hline Outpatient & $3.92(3.31,4.64)^{* *}$ & $1.13(0.92,1.39)$ & $2.14(1.92,2.38)^{* *}$ & $1.07(0.94,1.22)$ \\
\hline Other & $1.27(0.82,1.99)$ & $0.53(0.31,0.9)^{*}$ & $1.21(0.87,1.68)$ & $0.85(0.57,1.27)$ \\
\hline \multicolumn{5}{|l|}{ Length of stay (ref. $\leq 20$ days) } \\
\hline$(20,30]$ & $0.45(0.33,0.62)^{* *}$ & $0.45(0.33,0.62)^{* *}$ & $0.9(0.76,1.06)$ & $0.87(0.73,1.03)$ \\
\hline$(30,40]$ & $0.52(0.37,0.73)^{* *}$ & $0.46(0.32,0.66)^{* *}$ & $0.89(0.74,1.07)$ & $0.8(0.66,0.98)^{*}$ \\
\hline$(40,60]$ & $0.75(0.56,1.02)$ & $0.53(0.38,0.74)^{* *}$ & $1.13(0.94,1.35)$ & $0.89(0.73,1.08)$ \\
\hline$(60,100]$ & $4.35(3.47,5.46)^{* *}$ & $1.6(1.21,2.13)^{* *}$ & $3.12(2.63,3.71)^{* *}$ & $1.39(1.13,1.72)^{* *}$ \\
\hline$>100$ & $10.40(8.47,12.77)^{* *}$ & $3.27(2.46,4.35)^{* *}$ & $7.96(6.71,9.45)^{* *}$ & $2.29(1.82,2.89)^{* *}$ \\
\hline \multicolumn{5}{|l|}{ Hospital type } \\
\hline Tertiary hospitals (vs secondary hospitals) & $1.38(1.16,1.64)^{* *}$ & $2.61(2.04,3.35)^{* *}$ & $0.95(0.83,1.09)$ & $1.38(1.14,1.67)^{* *}$ \\
\hline Urban hospitals (vs rural; hospitals) & $0.15(0.13,0.17)^{* *}$ & $0.54(0.44,0.66)^{* *}$ & $0.33(0.3,0.37)^{* *}$ & $0.75(0.65,0.87)^{* *}$ \\
\hline
\end{tabular}

Notes: ${ }^{*} p<0.05$; ${ }^{*} p<0.001$; Number in the Table: Odds ratio (95\% confidence interval)

\section{Patient characteristics}

We found that being male, with a younger age and being unmarried were significantly associated with a higher risk of readmission. Such findings were consistent with the results of several other studies according to a systematic review published in 2016 [5]. This may reflect the differences in the symptom patterns and illness courses among patients with varied socio-demographic backgrounds [41]. An urban residency was found to be a risk factor for short-term and frequent readmissions, which was consistent with the results of Tami et al. [12] but since this factor had rarely been included, the mechanism behind such connection is unclear [5]. It may be confounded by the difference in income, education status, 
Table 3 Logistic regression of 1 -year frequent readmission ( $\geq 3$ times/1 year) $(N=2492)$

\begin{tabular}{|c|c|c|}
\hline & \multicolumn{2}{|c|}{ Frequent readmission in 1 year $(746 / 2492)$} \\
\hline & Univariate models & Multivariate model \\
\hline Male (ref. female) & $1.73(1.45,2.06)^{* *}$ & $1.3(1.04,1.64)^{*}$ \\
\hline \multicolumn{3}{|l|}{ Age (ref. (0-40]) } \\
\hline$(40,65]$ & $3.19(2.5,4.07)^{* *}$ & $1.06(0.77,1.46)$ \\
\hline$>65$ & $6.39(4.82,8.48)^{* *}$ & $1.26(0.84,1.89)$ \\
\hline \multicolumn{3}{|l|}{ Insurance type (ref. no insurance) } \\
\hline Urban employee & $5.22(3.22,8.47)^{* *}$ & $1.69(0.96,2.96)$ \\
\hline Urban resident & $1.88(1.05,3.35)$ & $1.2(0.61,2.34)$ \\
\hline New rural cooperative & $0.84(0.38,1.88)$ & $1.3(0.53,3.16)$ \\
\hline Other insurances & $2.14(1.21,3.8)$ & $0.92(0.47,1.81)$ \\
\hline Married (ref. not married) & $0.53(0.44,0.64)^{* *}$ & $0.89(0.68,1.15)$ \\
\hline Urban residents (ref. Suburb) & $2.66(2.1,3.36)^{* *}$ & $1.45(1.07,1.95)^{*}$ \\
\hline \multicolumn{3}{|l|}{ Diagnosis (ref. Depressive disorders) } \\
\hline Bipolar disorders & $0.65(0.4,1.05)$ & $0.47(0.27,0.82)^{* *}$ \\
\hline Schizophrenia and related disorders & $3.43(2.35,4.99)^{* *}$ & $0.78(0.49,1.26)$ \\
\hline Substance use disorders & $1.67(0.97,2.88)$ & $0.81(0.43,1.54)$ \\
\hline Other mental disorders & $3.28(2.15,5)^{* *}$ & $1.2(0.72,2.03)$ \\
\hline \multicolumn{3}{|l|}{ Count of comorbidities (ref. none) } \\
\hline 1 & $2.55(1.9,3.44)^{* *}$ & $1.59(1.11,2.27)^{*}$ \\
\hline$>1$ & $4.55(3.52,5.89)^{* *}$ & $1.95(1.4,2.71)^{* *}$ \\
\hline Use of ECT (ref. no ECT) & $0.19(0.14,0.26)^{* *}$ & $0.6(0.4,0.91)^{*}$ \\
\hline \multicolumn{3}{|c|}{ Psychiatric hospitalizations 1 year prior to index admission (ref. none) } \\
\hline 1 & $2.48(1.84,3.34)^{* *}$ & $1.66(1.19,2.32)^{* *}$ \\
\hline 2 & $10.55(8.08,13.79)^{* *}$ & $4.79(3.45,6.66)^{* *}$ \\
\hline$\geq 3$ times & $27.32(20.41,36.58)^{* *}$ & $10.02(7.05,14.24)^{* *}$ \\
\hline \multicolumn{3}{|l|}{ Admission sources (ref. emergency room) } \\
\hline Outpatient & $4.23(3.24,5.53)$ & $1.29(0.91,1.82)$ \\
\hline Other & $0.95(0.39,2.3)$ & $0.93(0.32,2.75)$ \\
\hline \multicolumn{3}{|l|}{ Length of stay (ref. $\leq 20$ days) } \\
\hline$(20,30]$ & $0.63(0.38,1.05)$ & $0.62(0.36,1.08)$ \\
\hline$(30,40]$ & $0.96(0.57,1.62)$ & $0.84(0.47,1.49)$ \\
\hline$(40,60]$ & $1.66(1.06,2.58)^{*}$ & $1.3(0.79,2.14)$ \\
\hline$(60,100]$ & $8.13(5.65,11.68)^{* *}$ & $2.48(1.56,3.95)^{* *}$ \\
\hline$>100$ & $6.01(4.26,8.47)^{* *}$ & $1.26(0.79,2.01)$ \\
\hline \multicolumn{3}{|l|}{ Hospital type } \\
\hline Tertiary hospitals (vs secondary hospitals) & $2.24(1.68,2.99)^{* *}$ & $2.3(1.51,3.51)^{* *}$ \\
\hline Urban hospitals (vs rural hospitals) & $0.21(0.17,0.26)^{* *}$ & $0.86(0.62,1.19)$ \\
\hline
\end{tabular}

Notes: ${ }^{*} p<0.05 ;{ }^{* *} p<0.001$; Number in the Table: Odds ratio (95\% confidence interval)

care-giving method, insurance coverage, family support and neighborhood environment between the urban and rural residency. It may reflect a difference in service accessibility and availability as urban residents tend to have better resources and access to psychiatric care.

With respect to the LOS, we found the LOS in China (mean: 66.90 days) was considerably longer than that in many developed countries (mostly less than 40 days) [2, 4, 42]. This reflects the reality that psychiatric hospitalization remains a primary source of treatment for many patients and that there is an urgent need to expand communitybased mental health services $[2,43,44]$.

Our findings provide an opportunity to further examine the effects of different LOS on risk of readmission. 
Compared with patients with LOS less than 20 days, patients with LOS between 20 to 60 days had a lower readmission risk while the ones with LOS $>60$ days had a higher risk. This may suggest that the optimal LOS is between 20 and 60 days in the study population although further studies are needed in this area. It is reasonable to assume that for the patients with LOS longer than 60 days, they were more likely to have a more severe disorder, and they were more likely to be treatmentresistant and to have limited family or social support.

\section{The use of electroconvulsive therapy (ECT)}

The study found that the use of ECT was significantly associated with a low risk of the 30-day and frequent readmissions in the entire sample and among the patients with schizophrenia and related disorders. Among the patients with affective disorders (depressive and bipolar disorders), a trend of association was found between ECT treatment and a low risk of readmission but the association was not statistically significant.

ECT is widely used in China and unlike in United States, where ECT is predominantly used for patients with major depressive disorder, it is used in patients with numerous other psychiatric disorders, with schizophrenia and mood disorders being the two most common indications $[45,46]$.

Our findings about the association between ECT and readmission risk are important and intriguing. It is important because we found that ECT was associated with a lower risk of readmission in the whole sample including patients from 10 hospitals, and in the sample with schizophrenia and related disorders. It is intriguing because the association was not significant among patients with affective disorders, which is inconsistent with the findings by Slade et al. (2017) [15], who found the use of ECT was significantly associated with reduction of 30day readmission risk in 162,691 US patients with severe affective disorders from 9 states [15]. Our findings are also different from another study in China (Ma et al. (2019)), which analyzed discharge data in one psychiatric hospital in Guangzhou city, and found no significant association between the use of ECT and the risk of 6month readmissions [46].

These discrepancies may due to different inclusion and diagnostic criteria, varied ECT utilization rates (our study: 27\%; Ma 2019: 17.8\%; Slade 2017: 1.5\%) and even different treatment parameters in different studies. Other factors, such as other treatments (including medications) during the index admissions, and the number of ECT treatments, may also play a role. Although the current finding of this study may suggest that ECT is an effective treatment in reducing the risk of readmissions in the study population, it is also possible that patients or their families are avoidant of future admissions, due to actual or perceived side effects or other reasons (such as stigma or fear) related to ECT treatments. Unfortunately, we do not have the relevant data to further understand the mechanism behind the findings.

Clearly, the association between ECT and readmission rate warrants further research. Since the association between ECT use and the risk of readmission can be disorder and study setting specific (rate of utilization varies), future studies may need to include more details, such as data on the patients' symptoms, medication use, treatment parameters, adverse events during the procedure, etc. [47].

\section{Hospital characteristics}

We found that index admission in tertiary hospitals was significantly associated with 30-day and frequent readmissions in this study. This could be explained by the fact that patients treated in the tertiary hospitals tended to be more severe and treatment-resistant, and such severity was not fully adjusted for using the existing variables in the multi-variate model. Previous studies using data from the Centre of Medicare and Medicaid Services (CMS) in United States had identified that larger, urban, academic facilities tended to have slightly higher riskstandardized readmission rates [48, 49]. In this study, tertiary hospitals in China normally had more hospital beds and higher service volumes so that the finding of this research was in line with the results of previous studies. On the other hand, compared with admission at rural hospitals, admission at urban hospitals was associated with a low risk of readmission in this study, this may suggest that urban hospitals may provide better services or are better at discharge planning or service coordination. Further studies may try to include more psychiatric hospitals located in more regions of China, so that more institutional characteristics, like staffing levels [50] and geographical variables can be incorporated into the analyses.

\section{Strengths and limitations}

One of the strengths of this study is that we utilized the regional all-payer medical record database from 2015 to 2017, providing evidences on the 30-day, 1-year and frequent readmissions of psychiatric patients in Beijing. The sample is very large $(>7000)$ and multiple hospitals in different levels (tertiary versus secondary) and different setting (urban versus rural) were included. The regional multi-center database in this study is better than data from a single hospital, as it may detect readmissions across hospitals and institutional factors can be examined as well.

Another strength is the rigorousness of inclusion/exclusion criteria and the inclusion of ECT treatment in the analysis. For example, we excluded patients with 
unusual LOS $(<24 \mathrm{~h})$ and patients who were non-Beijing residents to reduce the bias introduced by patients admitted for rehabilitation purposes or patients travelled to Beijing for treatments.

A few limitations also need to be acknowledged. Firstly, since we only used data from the face sheets of discharge medical records, we were unable to include several potentially important factors. For example, we were unable to include demographic factors such as employment, income, living situation and education levels; clinical factors such as the severity of the psychiatric symptoms, the status of voluntarily versus involuntary admission, patients' response to medications; as well as post-discharge factors like medication adherence, support system etc. While this study proved that face sheets of medical records can be used as a cost-effective way to examine factors associated with readmission risk, further prospective studies are needed to replicate our findings and explore the mechanism behind the associations between the identified factors and the readmission risk. Due to the limitation of our dataset, some of our findings, especially the findings regarding ECT treatment, should be interpreted with caution, since we only used ECT treatment as a categorical variable (yes or no). Future studies need to include treatment-related factors, including number of treatments, legal status, treatment parameters (such as electrode placement, charge, etc.) and adverse events.

Secondly, we did not have access to the outpatient records of those patients thus we were unable to examine the outpatient service utilization after the index admissions. We also did not have information on the community care availability and intensity [26] so we were unable to examine their effects on the risk of readmission or incorporate these factors in the risk-adjustment models. We also did not include patient readmissions due to physical illnesses so the psychiatric readmission rate estimated in this study may be lower than the all-cause readmission rates among psychiatric inpatients [51].

Thirdly, since this study used data from Beijing, the capital city of China and it is considered as a regional and even national medical center with better resources, the results of this study may not be generalizable to other parts of the country, especially less developed regions. A national database or a national represented sample of psychiatric patients would be more ideal data sources for future studies.

\section{Conclusions}

This study estimated that the rate of 30-day and 1-year psychiatric readmission was 16.69 and $33.79 \%$ respectively; and $10.12 \%$ were considered as frequent readmissions ( $\geq 3$ admissions within 12 months after discharge).
Those who resided in an urban area, with medical comorbidities, previous psychiatric admissions, and length of stay of $>60$ days in the index admissions were more likely to have psychiatric readmissions. Receiving ECT treatment may be associated with a lower risk of readmission.

Further studies might consider exploring the clinical and epidemiological mechanisms behind the risk and protective factors for readmission or designing interventions at hospital and community levels to reduce psychiatric readmission in China.

\section{Supplementary information}

Supplementary information accompanies this paper at https://doi.org/10. 1186/s12888-020-02515-1.

Additional File 1. Results of supplementary analyses and the list of comorbidities included in the Elixhauser Comorbidity Index (ECI). Supplementary Table 1 listed the comorbidities of ECI. Supplementary Table $2-4$ showed the results of the supplementary descriptive and univariate analyses. Supplementary Table 5-7 presented the results of the sensitivity analyses. Supplementary Table 8-9 showed the results for post-regression diagnostics and calibration plots of the primary and sensitivity analyses models.

\section{Abbreviations \\ AHRQ: Agency for Healthcare Research \& Quality (United States); $\mathrm{Cl}$ : Confidence interval; ECT: electroconvulsive therapy; ICD: International Classification of Diseases; LOS: Length of stay; OR: Odds ratio}

\section{Acknowledgements}

We thank the data management team of Beijing Municipal Health Commission Information Centre for their efforts in collecting and vetting the original datasets. We appreciate Dr. A. Umair Janjua, MD from Emory University for his efforts in reviewing and revising the manuscript. We are also grateful for the methodologists and statisticians at the Peking Union Medical College for offering technical consultation for this paper.

Ethics approval and consent to participate

This project was approved by the Ethics Committee of Chinese Clinical Trial Registry (ChiECRCT-20,180,166). The informed consent of patients was waived.

Consent to publication

Not applicable.

\section{Authors' contributions}

$X H, F J, H Z$, and $Y L$ conceived the study. MG and YC coordinated data collection and initial data cleansing. $\mathrm{XH}$ and FJ polished study design and the statistical models. XH conducted data analyses and completed the first draft. $H Z, F J, Y T, J N$ and $Y L$ revised and polished the manuscript. All authors had full access to all the data in this study and approved the publication of the paper.

\section{Funding}

This research was funded by China Medical Board (CMB-OC (2018) 17-278). The funding agency had no further role in the study design, data analysis and interpretation, the manuscript drafting or the decision to submit the article for publication.

\section{Availability of data and materials}

The data used in this study were obtained from the inpatient medical record (face sheets) database of Beijing Municipal Health Commission Information Centre and was not publicly available. Contact information the Information Centre can be found on http://www.phic.org.cn/tjsj/. 


\section{Competing interests}

The authors declare that they have no competing interests.

\section{Author details}

'School of public health, Chinese Academy of Medical Sciences and Peking Union Medical College, No.3 Dong Dan San Tiao, Dongcheng District, Beijing, China. ${ }^{2}$ Department of Psychiatry and Behavioral Sciences, Emory University, 12 Executive Park Drive NE, Suite, Atlanta, GA 300, USA. ${ }^{3}$ Atlanta VA Medical Center, 1670 Clairmont Road, Decatur, GA, USA. ${ }^{4}$ Department of Health Policy and Management, UCLA Fielding School of Public Health, 650 Charles Young Dr. S., 31-269 CHS Box, Los Angeles, CA 951772, USA. ${ }^{5}$ Beijing Municipal Health Commission Information Centre, No. 277 Zhao Deng Yu Lu, Xicheng District, Beijing, China. ${ }^{6}$ Peking University International Hospital, No. 29 Sheng Ming Yuan Lu, Haidian District, Beijing, China. ${ }^{7}$ School of Sport Science, Beijing Sport University, No. 48 Xin Xi Lu, Haidian District, Beijing, China.

Received: 2 April 2019 Accepted: 26 February 2020

Published online: 11 March 2020

\section{References}

1. Huang $Y$, Wang $Y$, Wang H, Liu Z, Yu X, Yan J, Yu Y, Kou C, Xu X, Lu J, et al. Prevalence of mental disorders in China: a cross-sectional epidemiological study. Lancet Psychiatry. 2019;6(3):211-24.

2. Zhou Y, Arosenheck R, Mohamed S, Fan N, Ning Y, Hongbo HE, Institute N, Hospital GP, University GM, Psychiatry DO: Retrospective assessment of factors associated with readmission in a large psychiatric hospital in Guangzhou, China. Shanghai Arch Psychiatry 2014, 26(3):138-148.

3. Vigod SN, Kurdyak PA, Seitz D, Herrmann N, Fung K, Lin E, Perlman C, Taylor $\mathrm{VH}$, Rochon PA, Gruneir A. READMIT: a clinical risk index to predict 30-day readmission after $F$ from acute psychiatric units. J Psychiatr Res. 2015;61: 205-13.

4. Rieke K, McGeary C, Schmid KK, Watanabe-Galloway S. Risk factors for inpatient psychiatric readmission: are there gender differences? Community Ment Health J. 2016:52(6):675-82.

5. Donisi V, Tedeschi F, Wahlbeck K, Haaramo P, Amaddeo F. Pre-discharge factors predicting readmissions of psychiatric patients: a systematic review of the literature. BMC PSYCHIATRY. 2016;16(1):449.

6. Machado V, Leonidas C, Santos MA, Santos MA. Psychiatric readmission: an integrative review of the literature. Int Nurs Rev. 2012;59(4):447-57.

7. Evans $L$, Harris $V$, Newman L, Beck A. Rapid and frequent psychiatric readmissions: associated factors. INT J PSYCHIAT CLIN. 2017;21(4):271-6.

8. Han KT, Lee SY, Kim SJ, Hahm MI, Jang SI, Kim SJ, Kim W, Park EC. Readmission rates of south Korean psychiatric inpatients by inpatient volumes per psychiatrist. BMC PSYCHIATRY. 2016;16:96.

9. Kalseth J, Lassemo E, Wahlbeck K, Haaramo P, Magnussen J. Psychiatric readmissions and their association with environmental and health system characteristics: a systematic review of the literature. BMC PSYCHIATRY. 2016; 16(1):376.

10. Baeza F, Da RN, Fleck M. Readmission in psychiatry inpatients within a year of discharge: the role of symptoms at discharge and post-discharge care in a Brazilian sample. Gen Hosp Psychiatry. 2018;51:63-70.

11. Langdon PE, Yágüez L, Brown J, Hope A. Who walks through the 'revolvingdoor' of a British psychiatric hospital? J Ment Health. 2001;10(5):525.

12. Mark T, Tomic KS, Kowlessar N, Chu BC, Vandivort-Warren R, Smith S. Hospital readmission among Medicaid patients with an index hospitalization for mental and/or substance use disorder. The Journal of Behavioral Health Services \& Research. 2013;40(2):207-21.

13. Urach C, Zauner G, Wahlbeck K, Haaramo P, Popper N. Statistical methods and modelling techniques for analysing hospital readmission of discharged psychiatric patients: a systematic literature review. BMC PSYCHIATRY. 2016; 16(1):413.

14. Sprah L, Dernovsek MZ, Wahlbeck K, Haaramo P. Psychiatric readmissions and their association with physical comorbidity: a systematic literature review. BMC PSYCHIATRY. 2017;17(1):2.

15. Slade EP, Jahn DR, Regenold WT, Case BG. Association of Electroconvulsive Therapy with Psychiatric Readmissions in US hospitals. JAMA PSYCHIAT. 2017:74(8):798-804.

16. Jaramillo-Gonzalez LE, Sanchez-Pedraza R, Herazo MI. The frequency of rehospitalization and associated factors in Colombian psychiatric patients: a cohort study. BMC PSYCHIATRY. 2014;14:161.
17. Reddy M, Schneiders-Rice S, Pierce C, Fitzmaurice G, Busch A. Accuracy of prospective predictions of 30-day Hospital readmission. Psychiatr Serv. 2016; 67(2):244-7

18. Jiang F, Liu T, Zhou H, Rakofsky JJ, Liu H, Liu Y, Tang Y. Developing medical record-based, healthcare quality indicators for psychiatric hospitals in China: a modified Delphi-analytic hierarchy process study. International journal for quality in health care : journal of the International Society for Quality in Health Care. 2019

19. Shi C, Ma N, Wang L, Yi L, Wang X, Zhang W, Wang B. Study of the mental health resources in China [in Chinese]. Chinese Journal of Health Policy. 2019;2(12):51-7.

20. Que J, Lu L, Shi L. Development and challenges of mental health in China. General Psychiatry. 2019;32(1):e100053.

21. Zhang W, Li X, Lin Y, Zhang X, Qu Z, Wang X, Xu H, Jiao A, Guo M, Zhang Y, et al. Pathways to psychiatric care in urban North China: a general hospital based study. INT J MENT HEALTH SY. 2013;7(1):22.

22. Liu J, Ma H, He YL, Xie B, Xu YF, Tang HY, Li M, Hao W, Wang XD, Zhang MY, et al. Mental health system in China: history, recent service reform and future challenges. World Psychiatry. 2011;10(3):210-6.

23. Fang $M$, Hall BJ, Lin $Y$, Hu SX. Structural changes to enhance mental health Services in China: experience and challenges. Asian J Psychiatr. 2019;43:177_ 8.

24. National Health Commission of China: National Report on the Services, Quality and Safety in Medical Care System 2017 (in Chinese). Beijing: Scientific and Technical Documentation Press; 2018

25. Li Q, Su Y, Xiang Y, Shu L, Yu X, Ungvari GS, Seiner SJ, Chiu HFK, Ning Y, Wang $G$, et al. Electroconvulsive therapy in schizophrenia in China. The Journal of ECT. 2017;33(2):138-42.

26. Zhang Y, Dai G: Predictors of re-hospitalization over a two-year follow-up period among patients with schizophrenia enrolled in a community management program in Chengdu, China Shanghai Archives of Psychiatry 2012, 24(1):30-37.

27. Cai MY, Chen YH, Wang XD: The treatment strategies and influencing factors for readmission of schizophrenia patients (in Chinese). Journal of Traditional Chinese Medicine Management 2016, 24(12).

28. Wang SY. Clinical study of multiple factors affecting women's hospital readmission in patients with schizophrenia (in Chinese). China Health Standard Management. 2015:6(10):37-8.

29. Guo JZ, Wang WP, Cheng XQ, Yang Y: An analysis of hospital stays and readmissions within 1 year after discharge in patients with schizophrenia (in Chinese). J Psychiatry 2017, 30(6).

30. Ma XM, Shi X, Huang LH, Ye CL, Zhang XP. Relationship between readmission rate and guardians in psychiatric community rehabilitation patients (in Chinese). Smart Healthcare. 2018;4(20):63-4.

31. Yip W, Hsiao W. Harnessing the privatization of China's fragmented healthcare delivery. LANCET. 2014;384(9945):805-18.

32. Jian $W$, Huang $Y$, Hu $M$, Zhang $X$. Performance evaluation of inpatient service in Beijing: a horizontal comparison with risk adjustment based on diagnosis related groups. BMC Health Serv Res. 2009;9:72.

33. National Health Commission of China: 2018 National Health Statistic Yearbook (in Chinese). Beijing: Peking Union Medical College Press; 2018

34. Moore BJ, White $\mathrm{S}$, Washington $\mathrm{R}$, Coenen $\mathrm{N}$, Elixhauser $\mathrm{A}$. Identifying increased risk of readmission and in-hospital mortality using Hospital administrative data: the AHRQ Elixhauser comorbidity index. Med Care. 2017;55(7):698-705.

35. Walraven CV, Austin PC, Jennings A, Quan H, Forster AJ. A modification of the Elixhauser comorbidity measures into a point system for Hospital death using administrative data. Med Care. 2009;47(6):626-33.

36. Wu L, Zhu H, Ghitza UE. Multi-comorbidity of chronic diseases and substance use disorders and their association with hospitalization: results from electronic health records data. DRUG ALCOHOL DEPEN. 2018;192:316-23.

37. Forthman MT, Gold RS, Dove HG, Henderson RD. Risk-adjusted indices for measuring the quality of inpatient care. Qual Manag Health Care. 2010;19(3): 265-77.

38. Fenlon C, O Grady L, Doherty ML, Dunnion J: a discussion of calibration techniques for evaluating binary and categorical predictive models. PREV VET MED 2018, 149:107-114.

39. Hewlett E, Moran V. Making mental health count (report of Organization for Economic Cooperation and Development); 2014. 
40. Yu C, Sylvestre JD, Segal M, Looper KJ, Rej S. Predictors of psychiatric rehospitalization in older adults with severe mental illness. Int J Geriatr Psychiatry. 2015;30(11):1114-9.

41. Tang Y, Gillespie CF, Epstein MP, Mao P, Jiang F, Chen Q, Cai Z, Mitchell PB. Gender differences in 542 Chinese inpatients with schizophrenia. Schizophr Res. 2007:97(1-3):88-96.

42. Moss J, Li A, Tobin J, Weinstein IS, Harimoto T, Lanctôt KL. Predictors of readmission to a psychiatry inpatient unit. COMPR PSYCHIAT. 2014;55(3): 426-30.

43. Jiwei Q. Mental health care in China: providing services for under-treated patients. Journal of Mental Health Policy \& Economics. 2012;15(4):179.

44. Zhang J, Harvey C, Andrew C. Factors associated with length of stay and the risk of readmission in an acute psychiatric inpatient facility: a retrospective study. Australian \& New Zealand Journal of Psychiatry. 2011; 45(7):578-85.

45. Tang $Y$, Jiang $W$, Ren $Y, M a X$, Cotes RO, McDonald WM. Electroconvulsive therapy in China. The Journal of ECT. 2012;28(4):206-12

46. Ma Y, Rosenheck R, Fan N, He H. Rates and patient characteristics of electroconvulsive therapy in China and comparisons with the United States. The Journal of ECT. 2019;35(4):251-7.

47. Medda P, Perugi G, Zanello S, Ciuffa M, Rizzato S, Cassano GB. Comparative response to electroconvulsive therapy in medication-resistant bipolar I patients with depression and mixed state. The Journal of ECT. 2010;26(2): 82-6.

48. Horwitz LI, Bernheim SM, Ross JS, Herrin J, Grady JN, Krumholz HM, Drye EE, Lin Z. Hospital characteristics associated with risk-standardized readmission rates. Med Care. 2017;55(5):528-34.

49. Horwitz LI, Wang Y, Altaf FK, Wang C, Lin Z, Liu S, Grady J, Bernheim SM, Desai NR, Venkatesh AK, et al. Hospital characteristics associated with postdischarge Hospital readmission, observation, and emergency department utilization. Med Care. 2018;1.

50. Al-Amin M. Hospital characteristics and 30-day all-cause readmission rates. J Hosp Med. 2016;11(10):682-7.

51. Han X, Jiang F, Zhou H, Needleman J, Guo M, Chen Y, Liu Y, Tang Y: Hospitalization Pattern, Inpatient Service Utilization and Quality of Care in Patients With Alcohol Use Disorder: A Sequence Analysis of Discharge Medical Records. ALCOHOL ALCOHOLISM 2019, pii: agz081. doi: https://doi. org/10.1093/alcalc/agz081. [Epub ahead of print]

\section{Publisher's Note}

Springer Nature remains neutral with regard to jurisdictional claims in published maps and institutional affiliations.

Ready to submit your research? Choose BMC and benefit from:

- fast, convenient online submission

- thorough peer review by experienced researchers in your field

- rapid publication on acceptance

- support for research data, including large and complex data types

- gold Open Access which fosters wider collaboration and increased citations

- maximum visibility for your research: over $100 \mathrm{M}$ website views per year

At $\mathrm{BMC}$, research is always in progress.

Learn more biomedcentral.com/submissions 